\title{
SYNCHRONOUS INTERACTIVE LIVE LECTURES VERSUS ASYNCHRONOUS INDIVIDUAL ONLINE MODULES. A COMPARATIVE ANALYSIS OF STUDENTS' PERCEPTIONS AND PERFORMANCES
}

\author{
DOI: http://dx.doi.org/10.17159/2223-0386/2020/n24a4
}

\author{
Karel Van Nieuwenhuyse \\ University of Leuven, Leuven, Belgium \\ karel.vannieuwenhuyse@kuleuven.be \\ ORCID No.: 0000-0001-6901-0555
}

\begin{abstract}
Interactive and collaborative learning in 'live' and online (synchronous and asynchronous) environments generates an influence on the perception, motivation and outcomes of learning among students. From that theory, the aim of this contribution is to analyse the effects of different teaching approaches unexpectedly provoked by the COVID-19 pandemic. The object of this study is a master's course titled "History and Education" of which half the classes were taught via synchronous live lectures in an interactive and collaborative group condition and half via asynchronous digital modules to be individually completed without interaction or collaboration. The effects of those different conditions on students' perception of the comprehensibility and ease of studying the course, on students' interest, motivation and efforts, and on their learning performance was examined via a descriptive and exploratory case study using a questionnaire and the outcomes of a written examination. In the questionnaire, the course students had to score both conditions for several issues and explain their scores. The results show that the live lectures obtained better average scores than the digital modules, except for the perception of the ease of studying the course. Also, more students attributed higher scores to the live lectures on each issue, again except for the perception of the ease of studying the course. The learning performances did not generate differences between the two conditions. These results are discussed within the existing research and reflected upon in the light of the continuous pandemic forcing higher education to combine different shapes of teaching.
\end{abstract}

Keywords: Highere education; Interactive and collaborative learning; (A)Synchronous learning; Online learning; Teacher presence; History education.

\section{Introduction}

Learning, as the theory of constructivism states, is an active and 
constructive process. ${ }^{1}$ Social constructivism adds to this powerful insight by pointing to the social dimensions of learning and by incorporating the role of others into the learning process. ${ }^{2}$ It refers to learning as an interactive and collaborative process. In the past six decades, an extensive body of literature has been published, showing that interactive and collaborative learning generates positive learning outcomes compared to individual learning. ${ }^{3}$ Interaction and collaboration can increase students' interest, motivation and study effort for, amongst others, students long to be socially responsible and to form social relationships with their peers. ${ }^{4}$ The selfdetermination theory states that together with a sense of competence and autonomy, connectedness is also a basic need of learners that needs to be met in order to reinforce motivation in all learning contexts. ${ }^{5}$ Furthermore, by providing the necessary support and interaction with qualified others (such as the lecturer or fellow students), interactive and collaborative learning exercises an influence on the quality and outcomes of learning and on students' learning performances. At the same time, however, research shows that collaborative learning does not automatically generate good (or better) learning outcomes. To accomplish that, several conditions have to be met such as meaningful interaction aimed at fostering an understanding of the topic under study. ${ }^{6}$

Particularly since the 1990s, a very important extra dimension has been added to the research into the effects of interactive and collaborative learning, namely that of computer-supported (online) learning. Research has been conducted into the role of computer-supported collaborative

1 JD Bransford, Al Brown \& RR Cocking, How people learn: Brain, mind, experience, and school (Washington (DC), National Academies Press, 2000); CT Fosnot, "Constructivism: A psychological theory of learning", CT Fosnot (ed.), Constructivism: Theory, perspectives and practice (New York (NY), Teachers College Press, 1996), pp. 8-33.

2 LS Vygotsky, Thought and language (Cambridge MA, MIT Press, 1962).

3 DW Johnson \& RT Johnson, "An educational psychology success story: Social interdependence theory and cooperative learning", Educational Researcher, 38(5), 2009, pp. 365-379; Y Lou, PC Abrami, JC Spence, C Poulson, B Chambers \& S d'Apollonia, "Within-class grouping: A meta-analysis", Review of Educational Research, 66, 1996, pp. 423-458.

4 H Patrick, L Hicks \& AM Ryan, "Relations of perceived social efficacy and social goal pursuit to selfefficacy for academic work", Journal of Early Adolescence, 17(2), 1997, pp. 109-128; K Wentzel \& A Wigfield, "Academic and social motivational influences on students' academic performance", Educational Psychology Review, 10, 1998, pp. 155-175.

5 RM Ryan \& EL Deci, "Self-determination theory and the facilitation of intrinsic motivation, social development, and well-being", American Psychologist, 55, 2000, pp. 68-78; EL Deci \& RM Ryan, "Motivation, personality, and development within embedded social contexts: An overview of selfdetermination theory", RM Ryan (ed.), Oxford handbook of human motivation (Oxford UK, Oxford University Press, 2012), pp. 85-107.

6 DW Johnson \& RT Johnson, "Cooperation and the use of technology", DH Jonassen (ed.), Handbook of research on educational communications and technology, (Mahwah NJ, Erlbaum, 2004), pp. 785-811. 
learning environments, into the differences between small group and individual learning with technology, into online and distance education in various interactive and collaborative conditions, and into the effects of synchronous and asynchronous learning. ${ }^{7}$ Here, too, positive effects of interactive and collaborative learning emerge, albeit again subject to conditions, for example, that attention is paid to individual accountability; that media should support collaborative discussion in order to be more effective; that interaction and collaboration are to be included in asynchronous learning conditions in order to make them effective; and that the instructor should take up an active role in online or distance education in order to influence students' performances.

In short, interactive and collaborative learning can have positive effects on learning processes and learning outcomes in both synchronous and asynchronous conditions. This two-fold issue of collaborative interactive versus individual learning and of synchronous versus asynchronous learning environments became urgent in the spring of 2020 due to the outbreak of the COVID-19 pandemic. This crisis imposed an obligation on educational institutions worldwide to switch immediately from synchronous live lectures to asynchronous digital conditions as on-campus live education was immediately suspended in many countries.

Apart from the difficulties accompanying the "digital switch" that had to be made, the extraordinary circumstances due to the COVID-19 pandemic allowed, at the same time, an opportunity to analyse the effects of different teaching approaches within one course, in terms of physical live or synchronous lectures versus online asynchronous conditions and of interactive and collaborative versus individual learning. This contribution, being part of a special issue addressing "teaching and learning history in the time of the COVID-19/coronavirus pandemic", reports on such an analysis. The course used as the object of this analysis is a master's of history at the University of Leuven (situated in Flanders, the northern Dutch-speaking part of Belgium) titled "History and Education", which

7 Y Lou, PC Abrami \& S d'Apollonia, "Small group and individual learning with technology: A metaanalysis", Review of Educational Research, 71(3), 2001, pp. 449-521; K Kreijns, PA Kirschner \& W Jochems, "Identifying the pitfalls for social interaction in computer-supported collaborative learning environments: A review of the research", Computers in Human Behavior, 19(3), 2003, pp. 335-353; Y Lou, RM Bernard \& PC Abrami, "Media and pedagogy in undergraduate distance education: A theory-based meta-analysis of empirical literature", Educational Technology Research \& Development, 54(2), 2006, pp. 141-176; PC Abrami, RM Bernard, EM Bures, E Borokhovski \& R Tamim, "Interaction in distance education and online learning: Using evidence and theory to improve practice", Journal of Computing in Higher Education, 23(2/3), 2011, pp. 82-103. 
is taught by the author. ${ }^{8}$ Half of this course, dedicated to the history of secondary school history education in Belgium, was taught via interactive and collaborative synchronous live lectures; the other half, addressing an international perspective on history education, was offered via asynchronous online modules that had to be completed individually by the students. This allowed research to be conducted into the effects of both conditions on a number of learning issues. Students' perceptions of their interest, motivation and efforts to engage with the course in each of the two conditions was examined, as well as students' learning performances for both parts of the course. The specific circumstances of the digital switch halfway through the semester also allowed two additional issues to be examined. Because the two parts of the course titled "History and Education" were each taught in different ways, it was also possible to examine the perceived comprehensibility of the two parts of the course as well as the perceived ease of studying both parts by the students. The analysis made it possible to not only examine the effects of each condition on students' perceptions and performances, but also to compare both.

In what follows, first the research context, questions and methods are explained, then the results of the study are presented and discussed.

\section{Research context: History and education}

The course titled "History and Education" constitutes six credits (ECTS) and is offered within the Master of History programme and the Educational Master of Cultural Sciences-History Didactics programme, both at the University of Leuven (Belgium). That university mainly attracts students belonging to the White majority group in Belgium and the lower-middle-, upper-middle- and upper-classes of society. The course is particularly meant for prospective historians and history teachers and is an elective of both master's programmes. In the academic year 2019-2020, 15 students enrolled for the course: three female and 12 male students. All belonged, in terms of socio-economic status, to upper-middle-class households. The course consists of two parts. In the first part, the history of secondary school history education in the Low Countries (the current territory of Belgium and the Netherlands) since the end of the 18th century and in Belgium since its establishment in 1830 is addressed. The second part provides an analysis of secondary school history education in other countries around

8 For more information on the course, see https://onderwijsaanbod.kuleuven.be/2019/syllabi/v/e/F0VE1AE. htm\#activetab=doelstellingen_idm1561056, as accessed on 5 November 2020. 
the world. In particular, history education in the Netherlands, the United States, Russia, Rwanda, Israel and Palestine, and the Arabic Muslim world is studied. The focus is on recent and current societal debates and expectations about history education in those countries and on the influence of those debates on the shape and outlook of standards, curricula and textbooks for history education (in terms of main aims and content orientation). History education in this course is not examined through a history didactics lens. Rather, a cultural history perspective is taken, as the guiding questions are, How are the past and history approached in history education? Whose history is addressed and for what aims? And what does the relationship between the state, society and history education look like?

This course is scheduled in the second semester (between February and May) of the academic year and takes two hours a week over a period of 12 weeks. Half of the course is spent on the history of history education in Belgium, the other half on an international perspective on history education. The weekly two-hour classes are a combination of lecturing and collaborative and interactive learning that focuses on fostering an understanding of the topic being taught via, for instance, group work, Socratic dialogue and group debate, which is often centred around and starting from document analysis. All classes are accompanied by a PowerPoint presentation that serves as a basis for students who are expected to take notes themselves. A learning text is not provided.

However, because of the COVID-19 pandemic, the organisation of the classes had to change drastically. From mid-March onwards, the University of Leuven suspended all physical live classes and obliged all lecturers to make a digital switch. They had the choice to teach online, to design digital modules, to provide students with PowerPoint presentations and an accompanying voice-over, and so forth. For the course "History and Education", this meant that while the lessons on the history of history education in Belgium had been provided via physical live classes, the lessons on the international perspective on history education had to be offered in a digital manner. Therefore digital lesson modules were designed on Toledo, the e-learning platform of the University of Leuven. These modules had to be completed by the students individually, without collaborative learning activities; did not contain deadlines; and were set up in an asynchronous way so students were free to choose when precisely to complete them. This also meant that no collaborative or interactive educational activities such as discussion forums were provided. This shape of online education was 
chosen as it left students free to choose when to engage with the modules and at what pace. Some students still had to work on their theses and others on a pre-service internship in secondary education. This way, their agendas were not overloaded during weekdays.

Each of the six digital modules was built following the same outline. An introduction was offered in order to generate interest in the topic. It consisted of a news article, a quiz to test previous knowledge, a padlet gauging their opinion on a specific topic, ${ }^{9}$ etc. The main part of each digital module ensured an alternation between pieces of theory and assignments (often based on document analysis) followed by automatic feedback (in terms of a model answer) and sometimes a padlet to write down their opinions on a matter, which then became visible to the other students. The assignments were not mandatory: students could skip them if they preferred. As all students in the course were graduates and hence experienced students, it was left to them to decide whether to complete the assignments or not. The students were considered sufficiently experienced to judge this for themselves. At the end of each digital module, students were offered a learning text, containing all the content they needed to study for the written examination.

The written examination for this course consisted of two substantial questions. One encompassed a major thread in the history of history education in Belgium, such as the tension between disciplinary and citizenship goals, or the relationship between the secondary school subject of history and academic historiography. The other was a comparison between history education in different countries, for example, to what extent and via what strategies is history education meant to contribute to social cohesion, or how and why are professional historians included (or not) in giving shape to secondary school history education. ${ }^{10}$

\section{Research questions and methodology}

As half of the course was taught via live synchronous lectures in an interactive and collaborative group condition and half via digital modules

9 A padlet is an application to create an online bulletin board where students and teachers can display information, collaborate, reflect, and share links and pictures.

10 Besides this, students also had to write a paper as part of the evaluation, in which, based on at least two published academic papers, they had to elaborate either on an aspect of Belgian history education from a historical perspective, or on the outlook and shape of history education in a country in the world, not addressed in the course. This paper assignment is not included in the further analysis, as it has no connection with the different teaching approaches under study. 
to be individually completed asynchronously, this allowed time to examine the effects of the two different teaching approaches on students' perception of the comprehensibility and ease of studying the course; on students' interest, motivation and efforts; and on their performance for the course. In so doing, connection was sought to the vast body of literature on interactive and collaborative learning and its effects. This study contributes to that literature, as it examined a group of graduate students and compared two different conditions for one group (instead of using two groups and additional control groups to test the two conditions). The following research questions guided the analysis:

- What are the effects of the two different educational conditions on students' perceptions of the comprehensibility and ease of studying the course on students' interest and motivation and on the efforts they made to engage with the course?

- What are the effects of the two different educational conditions on students' performance for the course?

- What are the differences to be discerned when comparing the results of the two previous questions? Can differences be found between the two conditions in students' perceptions and performances and, if so, how should this be accounted for?

The comparison was explicitly included as a research question because it is highly possible that the two conditions might have generated substantial differences. With regard to comprehensibility of the course content (1), live lectures offered opportunities for the lecturer to provide explanations to the students; direct questions and answers for collaborative interaction; and direct feedback on the assignments. The digital modules, by contrast, could be completed by students at their own pace, asynchronously, without interaction, yet with automatic feedback (in terms of a model answer provided after each assignment) and with the provision of a learning text. In terms of the ease of studying the course (2), while the lectures were accompanied by PowerPoint presentations and live explanations, no learning text was included as the digital modules provided a learning text. With regard to interest in the course (3), while lectures were synchronous and live and included interaction and collaborative learning activities, the digital modules were asynchronous and could be completed at the students' own pace at a time that suited them best, yet individually. Regarding students' motivation to get started with assignments (4), the lectures required some reading beforehand, yet assignments were mostly 
completed during the lecture, in interaction with the lecturer and fellow students and according to a pace determined by the lecturer. In the digital modules, the assignments were done individually, at one's own pace and without being obligatory (cfr. supra for a justification in this respect). This means that while the effort (5) was included (and obligatory) in the lectures, the effort to complete the assignments in the digital modules was not obligatory. Lastly, all these issues could have generated an effect on students' performance (6) for the written examination related to this course as, on the one hand, students were provided with information by the lecturer during the live lectures (via PowerPoint presentation and explanation), yet, on the other hand, they obtained full learning texts in the digital modules.

In order to get a view on the above-mentioned issues, a descriptive and exploratory case study, including quantitative and qualitative elements, was set up. In particular, a questionnaire was designed in which students had to assess the live lectures as well as the digital modules with a score from one to ten on each of the issues under examination. The questionnaire included clear, unambiguous questions, such as, "How do you assess the comprehensibility of the learning content, in condition ...?" or "How do you assess the effect of condition ... on your motivation to engage with the learning content?" The unexpected character of the COVID-19 pandemic did not allow validation of the questionnaire in a pilot study. Nevertheless, it was checked to assess whether the questions were indeed well understood by the students by explicitly asking them if all questions had been clear (which was the case) and by checking whether the students' explanation accompanying their scores actually related to the questions (which was the case as well). Students were invited to explain their scores and to describe the differences or similarities they experienced between the teaching approaches. Furthermore, they were asked whether they had experienced big differences in the time they spent on the lectures versus the digital modules and whether they wanted to make additional comments relating to the different teaching approaches of the course. When the questionnaires were handed in just before the start of the examination period, a so-called anonymous other kept track of them, anonymised them, and then attached the scores on both examination questions to each student's questionnaire. In so doing, the anonymity of the students was guaranteed. The analysis was done in a qualitative way, in search of patterns in the students' answers.

The questionnaire was completed by 11 of the 15 students who enrolled for the course. Four students did not attend any of the classes as they 
took up teaching jobs in a secondary school on the day the course was normally taught. They were, therefore, removed from the analysis sample. This means that the analysis was done on the basis of 11 completed questionnaires, meaning 73 per cent of the students enrolled in the course participated in the research. Initially, the idea was to supplement the results stemming from the questionnaire with data from qualitative (individual or group) interviews. However, due to the COVID-19 pandemic, the June examination period at the University of Leuven was extended by two weeks, after which deliberations still had to be organised. As a result, because the students indicated that they wanted to leave on vacation immediately after receipt of their final results, it turned out to be impossible to organise such interviews.

\section{Results}

What are the effects of the two different educational conditions on students' perception of the comprehensibility and ease of studying the course, on students' interest and motivation, and on the efforts they made to engage with the course? And can differences be found related to those issues between the two conditions?

With regard to the participants' perceptions, the results show that the live lectures obtained better average scores for the perception of the comprehensibility of the course, for students' interest and motivation and for the efforts they made to engage with the course and then the digital modules. The only exception concerns the perception of the ease of studying the course: in this case, the digital modules obtained a (very slightly) higher score than the live lectures (see Table 1). Also, in general, more students attributed higher scores to the live lectures than to the digital modules on the above-mentioned issues, again except for the perception of the ease of studying the course (see Table 2).

When looking at the individual student level and scores instead of the overall level and average scores, it was found that three students attributed higher scores to the live lectures compared with the digital modules on each of the issues under study; one student did the opposite and systematically scored the digital modules higher than the live lectures on each issue; the other seven students attributed varying scores, although they assessed the live lectures on more issues with higher scores than the digital modules. In what follows, each of the issues and their scores are analysed. 
Table 1: The average score (out of 10) attributed for each issue to the live lectures and the digital modules.

\begin{tabular}{|l|c|c|}
\hline Issue & $\begin{array}{c}\text { Average score } \\
\text { attributed to the live } \\
\text { lectures (out of 10) }\end{array}$ & $\begin{array}{c}\text { Average score } \\
\text { attributed to the } \\
\text { digital modules } \\
\text { (out of 10) }\end{array}$ \\
\hline Comprehensibility & 9 & 8 \\
\hline Ease of studying & 8.2 & 8.3 \\
\hline Interest & 9.1 & 7.5 \\
\hline Motivation to get started with assignments & 7.7 & 6.1 \\
\hline Actual effort to complete the assignments & 8.5 & 5.9 \\
\hline
\end{tabular}

Table 2: The number (and percentage) of students attributing higher or equal scores for each issue to the live lectures and the digital modules.

\begin{tabular}{|l|c|c|c|c|}
\hline Issue & $\begin{array}{c}\text { Number of } \\
\text { students } \\
\text { attributing a } \\
\text { higher score to } \\
\text { live lectures }\end{array}$ & $\begin{array}{c}\text { Number of } \\
\text { students } \\
\text { attributing a } \\
\text { higher score to } \\
\text { digital modules }\end{array}$ & $\begin{array}{c}\text { Number of } \\
\text { students } \\
\text { attributing } \\
\text { both an equal } \\
\text { score }\end{array}$ & Total \\
\hline Comprehensibility & $8(73 \%)$ & $2(18 \%)$ & $1(9 \%)$ & $11(100 \%)$ \\
\hline Ease of studying & $4(36 \%)$ & $5(46 \%)$ & $2(18 \%)$ & $11(100 \%)$ \\
\hline Interest & $7(64 \%)$ & $1(9 \%)$ & $3(27 \%)$ & $11(100 \%)$ \\
\hline $\begin{array}{l}\text { Motivation to get started } \\
\text { with assignments }\end{array}$ & $8(73 \%)$ & $2(18 \%)$ & $1(9 \%)$ & $11(100 \%)$ \\
\hline $\begin{array}{l}\text { Actual effort to make the } \\
\text { assignments }\end{array}$ & $9(82 \%)$ & $1(9 \%)$ & $1(9 \%)$ & $11(100 \%)$ \\
\hline
\end{tabular}

Regarding the perception of the comprehensibility of the course content, students attributed the live lectures a $9 / 10$ on average, and the digital modules a score of 8/10. Eight students attributed a higher score to the live lectures, two to the digital modules and one student attributed both an equal score. Live lectures were hence preferred by the majority of students who indicated that they could better concentrate on the course content when listening during a live lecture or talk. Furthermore, they appreciated the possibility of being able to ask direct questions and receive an immediate answer, feedback or have a debate about it with fellow students. Also, they stated that the coherence and connections between historical facts and phenomena became clearer during the lectures, because the lecturer made them explicit while explaining, asking questions or debating points. The student who rated the digital modules higher on comprehensibility did so because the digital modules offered a clearer structure than the live 
lectures. According to him, the PowerPoint presentations during the live lectures were not able to reveal the structure of each lecture as clearly.

The perception of the ease of studying the course was the only issue on which the digital modules scored (very slightly) better than the live lectures. While students attributed 8.2/10 on average for the live lectures, the digital modules received a score of $8.3 / 10$. Four students attributed a higher score to the live lectures, while five did so to the digital modules; two students attributed both equal scores. Those students who expressed a preference for the digital modules regarding this issue did so because the modules provided them with a learning text. They indicated that this was very helpful, as it included everything they had to study. During live lectures, they stated, one had to take notes and if one paid less attention during a part of the lecture, one might miss crucial information. Other students, however, did not consider the presence of a learning text as contributing to the ease of studying the course. In their opinion, the live explanation of the lecturer made connections between the historical phenomena being addressed clearer and more explicit and helped them to distinguish the main points from the side issues. They hence preferred the live lectures.

A large majority of the students indicated that live lectures stimulated their interest more than the digital modules. While they attributed a score of $7.5 / 10$ on average to those modules, the live lectures were attributed a 9.1/10. Seven students rated the live lectures higher, one student preferred the digital modules, and three students attributed an equal score to each medium. While all students indicated they were interested in the course material, most of them nevertheless preferred an enthusiastic lecturer and collaborative interaction to the individual completion of the digital modules. The one student who indicated the opposite did so because he considered the international comparative perspective on history education much more interesting than the historical perspective of history education in Belgium. His preference for the digital modules was hence related to the specific content rather than to the particular teaching approach.

In terms of motivation to get started with assignments, the live lectures scored higher. While the students assessed live lectures with an average score of 7.7/10, the digital modules gained a score of 6.1/10. Eight students attributed a higher score to the live lectures, two students preferred the digital modules and one student attributed both an equal score. The advantage of digital modules, some students stated, was that they could 
complete them asynchronously, at their own pace, without experiencing any stress. For the rest, students particularly connected advantages to the live lectures. The interaction, cooperation, exchange of ideas and debates stirred more motivation and furthermore, fostered the quality of the reflection. The fact that assignments had to be completed during the lectures and were discussed together, increased the motivation as well, as students had the feeling that in so doing, their effort led to a tangible result.

The level of motivation to get started with assignments seemed to be reflected in the actual effort to complete the assignments. While students gave a score of $8.5 / 10$ on average to the live lectures for actually making the effort to complete the assignments, the average score attributed to the digital modules was 5.9/10. Moreover, nine students attributed the live lectures a higher score; one student did the opposite, and another student attributed equal scores. Students particularly pointed at the added value of the collaborative interaction during live lectures as the driver to complete the assignments before and during the lectures. Because of the absence of interactive cooperation in the asynchronous digital modules - this would have hindered the students completing the modules at their own pace - and automatic feedback in terms of a model answer being generated, students did not feel encouraged to complete the assignments. The only advantage of the digital modules, one student stated, was that they indeed allowed him to complete the assignments at his own pace.

What are the effects of the two different educational conditions on students' performance for the course? And can differences be found between the two conditions in students' performances?

In order to examine a possible effect of the two conditions on students' learning performance on the written examination, two substantial questions were asked, one encompassing a major thread in the history of history education in Belgium (which had been addressed during the live lectures), and one on a comparison between history education in different countries (which had been addressed in the digital modules). When looking at the scores for the two examination questions, at first glance no difference could be discerned. The average score for both questions was 13/20.

When looking at the individual student level, it was found that two students scored better for the question related to the content seen in the live lectures, while three scored better for the question related to the content of the digital modules (see Table 3). Six students gave the same score for both 
questions. It hence seems that, overall, the different teaching approaches did not clearly affect students' performance for the course.

Table 3: Individual examination scores per student on the two questions (related to contents addressed resp. in the live lectures and the digital modules).

\begin{tabular}{|c|c|c|}
\hline Student & $\begin{array}{c}\text { Score (out of 20) on exam question 1 } \\
\text { (content during live lectures) }\end{array}$ & $\begin{array}{c}\text { Score (out of 20) on exam question 2 } \\
\text { (content digital modules) }\end{array}$ \\
\hline 1 & 12 & 8 \\
\hline 2 & 14 & 14 \\
\hline 3 & 13 & 14 \\
\hline 4 & 14 & 14 \\
\hline 5 & 14 & 14 \\
\hline 6 & 14 & 16 \\
\hline 7 & 14 & 14 \\
\hline 8 & 14 & 14 \\
\hline 9 & 13 & 13 \\
\hline 10 & 12 & 14 \\
\hline 11 & 13 & 12 \\
\hline
\end{tabular}

\section{Conclusion and discussion}

The aim of this study was to examine the effects and influence of two different teaching approaches in a course titled "History and Education" on students' perception of the comprehensibility of and ease of studying the course, on their interest, motivation and effort to complete assignments, and on their performance in the written examination. The results show that the perception of the ease of studying the course and the performance in the examination were almost equal for the synchronous live lectures in which interactive and collaborative learning was present and the asynchronous digital modules that were completed individually. Regarding the perception of the comprehensibility of the course, differences were found in students' interest as well as their motivation and effort to complete assignments, in the sense that students attributed higher scores to the synchronous live lectures than to the asynchronous digital modules.

In interpreting the results, drawing conclusions and reflecting on consequences, caution is required. Several limitations of this study should be considered. The study concentrated on one course only, in which only a limited number of students were enrolled. All students belonged to uppermiddle-class households, meaning they probably had a quiet place in their 
home to engage with the digital modules and had easy online access on a device of their own, which they therefore did not have to share with other family members. Furthermore, all students were enrolled in a master's programme, meaning they were experienced students who had proved that they were capable of mastering graduate courses. The course, moreover, was an elective, belonging to the optional part of the programme, which normally means that students are intrinsically interested in the course. Another limitation is connected to the context in which the study took place. From mid-March 2020 onwards, due to the COVID-19 pandemic, all live lectures were suspended and all education had to take place in a digital format. This might have had an impact on the scores for the issues related to this course, for the students might not have considered the digital modules of the specific course "History and Education" alone, but rather the whole of digital education in that period. In that sense, a comparative design including other courses in the analysis would have been ideal. Several constraints, however, such as the fact that students belonged to different master's programmes and there was limited time between the launch of the call for papers and the submission of the paper, hindered us from doing so. The extent to which students' time investment in both the lectures and the digital modules might have influenced their scores is probably rather limited. While five students indicated they spent more time on the digital modules than on the lectures, three students indicated the opposite, and three other students considered their time investment equal. When relating the scores that students attributed to the different issues with regard to their time investment, no patterns could be discerned.

Although caution is thus needed, some findings are nevertheless worth discussing. The first is that no clear effect stemming from both teaching approaches could be found on students' performance for the written examination. At first glance, this confirms an earlier finding stating that collaborative learning during live lectures does not automatically generate better learning outcomes. To accomplish that, among other reasons, meaningful interaction aimed at fostering an understanding of the topic under study should be met. ${ }^{11}$ However, it should be stated that the interaction and collaboration during the live lectures were actually clearly focused on fostering an understanding of the topic being taught. How then to account for the absence of a difference in the examination performances? It needs

11 DW Johnson \& RT Johnson, "Cooperation and the use of technology", DH Jonassen (ed.), Handbook of research on educational communications and technology, (Mahwah NJ, Erlbaum, 2004), pp. 785-811. 
to be stressed that the participants in this study were experienced graduate students who had shown that they were capable of successfully studying a course. This might explain our finding. Moreover, the digital modules provided the students with a text in which everything they had to learn was included. That undoubtedly facilitated the learning of the content offered via the digital modules.

Second, findings from previous research related to interactive and collaborative learning and the effects of that learning seem to be confirmed in the analysis. The live lectures seemed to strongly reinforce students' interest, motivation and effort to complete assignments, as well as their perception of the comprehensibility of the course. Particularly when compared to the scores attributed to the digital modules on the issues at stake, the results illustrate the power of interaction and collaboration between students and with the lecturer. Students referred to this themselves in the closing comments section of the questionnaire where they had the opportunity to add personal reflections. Almost all students emphasised the necessity to include more interaction and cooperation between the students and lecturer in the digital modules, for instance, via short live sessions, via a live and synchronous discussion forum, or via a short summary knowledge clip, followed by a question and answer session. Asynchronous automated feedback by the lecturer accompanying the assignments students had to complete was considered insufficient. This certainly seems to confirm the self-determination theory of Ryan and Deci, which states that connectedness, next to a sense of competence and autonomy, is a basic need of learners. ${ }^{12}$ Moreover, that connectedness, according to the participating students, should take place in a live and synchronous manner, both between students and between students and lecturer. Indirect asynchronous connectedness, for example via a discussion forum where students can post comments and questions at one's own pace or with automated feedback, is clearly less appreciated.

Third, the conclusions of this study as well as suggestions that students made in the questionnaire are in line with previous research findings regarding online learning, namely that it is crucial that online learning processes include interaction and collaboration and, in doing so, offer support and scaffolding. ${ }^{13}$ That support can amongst others be realised

12 RM Ryan \& EL Deci, "Self-determination theory and the facilitation of...", American Psychologist, 55, 2000, pp. 68-78.

13 S Wilcox, "Fostering self-directed learning in the university setting", Studies in Higher Education, 21(2), 2006, pp. 165-176. 
via online "teacher presence", something the students pleaded for. ${ }^{14}$ This means that the asynchronous moments during which students work individually on the digital modules should be alternated with synchronous moments that offer opportunities to students for dialogue, collaboration, questions and answers, and feedback. In so doing, the asynchronous and the synchronous moments can reinforce each other's effects, and ultimately the learning process of students. When thinking of how to give shape to education during a continuous pandemic, characterised by an alternation between synchronous and asynchronous teaching and learning moments, seeking a balance between individual, interactive and collaborative learning certainly seems to constitute a successful way forward.

14 A Smits \& J Voogt, "Elements of satisfactory online asynchronous teacher behaviour in higher education", Australasian Journal of Educational Technology, 33(2), 2017, pp. 97-114; F Ke, "Examining online teaching, cognitive, and social presence for adult students", Computers and Education, 55(2), 2010, pp. 808-820. 